\title{
Ice supersaturation and the potential for contrail formation in a changing climate
}

\author{
E. A. Irvine and K. P. Shine \\ Department of Meteorology, University of Reading, Reading, UK \\ Correspondence to: E. A. Irvine (e.a.irvine@reading.ac.uk) \\ Received: 22 January 2015 - Published in Earth Syst. Dynam. Discuss.: 18 February 2015 \\ Revised: 3 July 2015 - Accepted: 8 August 2015 - Published: 2 September 2015
}

\begin{abstract}
Ice supersaturation (ISS) in the upper troposphere and lower stratosphere is important for the formation of cirrus clouds and long-lived contrails. Cold ISS (CISS) regions (taken here to be ice-supersaturated regions with temperature below $233 \mathrm{~K}$ ) are most relevant for contrail formation. We analyse projected changes to the $250 \mathrm{hPa}$ distribution and frequency of CISS regions over the 21st century using data from the Representative Concentration Pathway 8.5 simulations for a selection of Coupled Model Intercomparison Project Phase 5 models. The models show a global-mean, annual-mean decrease in CISS frequency by about one-third, from 11 to $7 \%$ by the end of the 21 st century, relative to the present-day period 1979-2005. Changes are analysed in further detail for three subregions where air traffic is already high and increasing (Northern Hemisphere mid-latitudes) or expected to increase (tropics and Northern Hemisphere polar regions). The largest change is seen in the tropics, where a reduction of around 9 percentage points in CISS frequency by the end of the century is driven by the strong warming of the upper troposphere. In the Northern Hemisphere mid-latitudes the multi-model-mean change is an increase in CISS frequency of 1 percentage point; however the sign of the change is dependent not only on the model but also on latitude and season. In the Northern Hemisphere polar regions there is an increase in CISS frequency of 5 percentage points in the annual mean. These results suggest that, over the 21 st century, climate change may have large impacts on the potential for contrail formation; actual changes to contrail cover will also depend on changes to the volume of air traffic, aircraft technology and flight routing.
\end{abstract}

\section{Introduction}

Regions of ice supersaturation (ISS) are a relatively common feature of the upper troposphere. Aircraft flying through ISS regions may form persistent contrails, which have been shown to contribute to anthropogenic climate change. Because they make a potentially large contribution to the climate impact of aviation (e.g. Lee et al., 2009), many studies have considered possible strategies to reduce contrail formation in the future, for example by developments to engine technology (Gierens et al., 2008; Haglind, 2008) or by changing aircraft altitude (Williams et al., 2002; Fichter et al., 2005; Mannstein et al., 2005; Rädel and Shine, 2008; Schumann et al., 2011; Deuber et al., 2013) or route (Sridhar et al., 2013; Irvine et al., 2014b; Soler et al., 2014; Zou et al., 2015) to avoid flying through ISS regions. In addition, it is likely that contrail formation will become more frequent due to increased air traffic, and the introduction of newer, more efficient engines, which consume less fuel but allow contrail formation to occur at higher temperatures and thus over a wider range of cruise altitudes than at present (Schumann, 2000; Schumann et al., 2000; Marquart et al., 2003). Using projected future air traffic scenarios, including an increase in engine propulsion efficiency, but with a present-day climate, Gierens et al. (1999) projected that global-mean contrail cover would increase by a factor of between 3 and 9 by 2050 (depending on the scenario used) relative to 1992.

One additional factor in determining future contrail cover which has received much less attention is how climate change itself may alter the likelihood of contrail formation by causing changes to the frequency and distribution of ISS regions. Minnis et al. (2004) analysed upper-tropospheric relative humidity trends, derived from reanalyses, for the period 1979-1995, over Northern Hemisphere mid-latitude regions, 
in the context of changes in contrail and cirrus occurrence. They found relative humidity decreases of up to $6 \%$ per decade, although they noted that data quality issues meant that these trends should be "viewed with some scepticism". Marquart et al. (2003) found that, in simulations for the year 2050 , climate change had a smaller impact on contrail cover than increasing air traffic. There was some regionality to the calculated changes in contrail cover; in the tropics the impact of climate change was important, but in the Northern Hemisphere mid-latitudes, a region where present-day air traffic is already high, an increase in air traffic was more important than any climate changes. Marquart et al. (2003) combined time-slice simulations from a single climate model with air traffic projections, both for 2050; together these increased the global-mean contrail cover by a factor of 3.7, relative to 1992. The present study makes use of the latest climate projections submitted to IPCC (2013), which extend out to 2100, allowing not only the assessment of changes to ISS over a longer time period but also an examination of the time evolution of these changes. Further, by comparing the results from multiple climate models, we can assess the robustness of our conclusions. Unlike the Marquart et al. (2003) and Gierens et al. (1999) studies, we do not attempt to calculate contrail cover using air traffic projections; the focus of this paper is the impact of climate change on ISS regions, independent of changes to air traffic, aircraft technology or routing. However, the close link between ISS and potential contrail cover has been clearly demonstrated by Burkhardt et al. (2008).

Regions of ISS are generally shallow and located close to the tropopause, which makes their global distribution highly variable with altitude. They are typically associated with ascending air streams (Gierens and Brinkop, 2012; Irvine et al., 2014a), such as those found in frontal systems and jet streams in the mid-latitudes or deep convection in the tropics (Kästner et al., 1999; Spichtinger et al., 2005; Gettelman et al., 2006; Luo et al., 2007; Irvine et al., 2012), as well as around high-pressure ridges (Immler et al., 2008; Gierens and Brinkop, 2012; Irvine et al., 2014a). The present-day global distribution of ISS regions, as determined by satellite and aircraft observations, tends to coincide with regions where these features occur. For example, in situ aircraft and satellite measurements around the highest aircraft cruise altitudes $(\sim 200 \mathrm{hPa})$ show the highest frequencies of ISS in the tropics, in regions with deep convection (Spichtinger et al., 2003b; Gettelman et al., 2006; Luo et al., 2007; Lamquin et al., 2012). High frequencies are also found to coincide with the mid-latitude storm tracks, where the frequency is highly variable with altitude (e.g. Irvine et al., 2012; Lamquin et al., 2012), and in high-latitude regions, particularly over the Southern Hemisphere polar regions (Gettelman et al., 2006; Lamquin et al., 2012).

The present-day distribution of ISS could be affected by climate change in two ways: firstly, via changes to humidity, and secondly via changes to temperature which may make a region too warm to support contrail formation. The consen- sus is that, under climate change, in the upper troposphere and lowermost stratosphere there will be a decrease in relative humidity in the tropics and increases towards the poles, with a transition at mid-latitudes (e.g. Lorenz and DeWeaver, 2007; Wright et al., 2010; Sherwood et al., 2010). This suggests that the pattern of the response of ISS regions to climate change will be regional rather than globally uniform. Wright et al. (2010) and Sherwood et al. (2010) discuss in detail the reasons for the changing distributions of relative humidity. Briefly, the tropical decrease is driven by the vertical and poleward expansion of Hadley circulation and the changes in temperature in regions where air parcels reaching the upper troposphere are last saturated. In the extratropics, changes in relative humidity are largely driven by temperature changes. In the context of contrails, a further mechanism is at play, because contrail formation is dependent on the air being below a given threshold temperature (Schumann, 1996 and see Sect. 2.2).

Climate models predict a general warming of the upper troposphere with climate change (e.g. Thorne et al., 2011), which is projected to be strongest in the tropics. Due to this warming, and since present-day temperatures at typical aircraft cruise altitudes in the tropics are often close to the threshold temperature for contrail formation, it is in the tropics that we might expect to see the largest impact of climate change on contrail cover, as was indeed found by Marquart et al. (2003). Outside of the tropics, the uppermost flight levels used by commercial aircraft are often in the lowermost stratosphere, particularly over the polar regions. Here climate models predict a general cooling, which is the main driver of the increased relative humidity, although the impact on threshold temperatures in the polar regions is likely limited since temperatures are generally well below those required for contrail formation.

This study analyses changes in ISS over the 21 st century in a selection of models from the Coupled Model Intercomparison Project Phase 5 (CMIP5) multi-model ensemble (Taylor et al., 2012). These data are described in Sect. 2.1. Data from simulations of the 21st century with a pathway of high greenhouse gas emissions (named RCP8.5 in the CMIP5 experiments) are compared to simulations of the present-day climate. ERA-Interim reanalysis data are used to evaluate the distribution of ISS in the present-day climate simulations of the CMIP5 models (Sect. 3.1). Changes to the global frequency and distribution of ISS are analysed for an end-ofcentury time period. The end-of-century change, as well as the time evolution of this change and its seasonal aspects, is analysed further for three regions of interest: the tropics, Northern Hemisphere (NH) mid-latitudes and $\mathrm{NH}$ polar regions (Sect. 3.2). Finally, since the daily-mean data used in this study are only available on a single pressure level relevant to contrail formation, monthly-mean data are used to understand whether the conclusions reached from the singlelevel data might be applicable to the range of aircraft flight altitudes (Sect. 3.3). Conclusions are presented in Sect. 4. 


\section{Method}

\subsection{Data}

Climate model data from the CMIP5 multi-model archive were used, from two simulations: historical and Representative Concentration Pathway (RCP) scenario 8.5 (Taylor et al., 2012). The historical simulation aims to reproduce the present-day climate by forcing the models with observed or simulated greenhouse gas and aerosol concentrations; for this study we take data from the historical simulation for the period 1979-2005. The RCP8.5 simulation uses economic scenarios to estimate future emissions of greenhouse gases and the resulting impacts on climate, for the period 2006-2099. RCP8.5 describes a world where there is little mitigation of greenhouse gas emissions, such that by 2100 , emissions reach 3 times their 2000 values (Riahi et al., 2011). This leads to a global-mean radiative forcing of $8.5 \mathrm{~W} \mathrm{~m}^{-2}$ and a surface temperature increase of about $4{ }^{\circ} \mathrm{C}$ by 2100 (IPCC, 2013). RCP 8.5 has the highest emissions and largest warming of the scenarios considered by IPCC (2013). This implies that we are analysing the maximum likely changes to ISS from climate change; more moderate emissions scenarios cause less warming, particularly in the second half of the 21 st century, and therefore an evaluation of these simulations would likely show smaller changes than in the RCP8.5 simulations.

For the purposes of this study, a selection of five CMIP5 models were chosen to analyse. Data were used from ECEARTH (Hazeleger et al., 2010, 2012), GFDL-ESM2G (Dunne et al., 2012), HadGEM2-CC (Martin et al., 2011; Collins et al., 2011), MIROC5 (Watanabe et al., 2010) and MPI-ESM-MR (Stevens et al., 2013). These models have been shown to have a good representation of key circulation features (Lee and Black, 2013; Davini and Cagnazzo, 2013). In addition, EC-EARTH was chosen because it explicitly represents ISS in its cloud scheme (it is based on a similar version of the European Centre for Medium-Range Weather Forecasts (ECMWF) forecast model to ERA-Interim; a description of the model version is given in Hazeleger et al., 2012). The resolution of the CMIP5 models used ranges from 1.2 to $2.0^{\circ}$ (Table 1). The greater part of this study uses daily-mean global data, for which data are available only on a limited number of pressure levels (in the UTLS regions these are 500, 250, 100 and $50 \mathrm{hPa}$, with each CMIP5 modelling group interpolating to these pressures from their own model's grid). Data are used on the $250 \mathrm{hPa}$ level, as this corresponds most closely to typical aircraft cruise altitudes and so is most appropriate to study changes in ISS that are relevant to aircraft contrail formation (see e.g. Wilkerson et al., 2010, who show peak emissions at about $10.5 \mathrm{~km}$, with the vast majority of flights cruising at between 10 and $12 \mathrm{~km}$; about 200$260 \mathrm{hPa}$ ). We note that even the use of daily data will fail to resolve ice-supersaturated regions with shorter lifetimes. To investigate whether the changes seen at the $250 \mathrm{hPa}$ level might also be observed at other cruise altitudes, monthlymean relative humidity data archived for each model were used; these data are available on seven pressure levels between 500 and $100 \mathrm{hPa}(500,400,300,250,200,150$ and $100 \mathrm{hPa})$.

For an evaluation of regions of high humidity in the historical simulations of the CMIP5 models, reanalysis data from the ECMWF Interim reanalysis (ERA-Interim; Dee et al., 2011) were used. Daily-mean data at a pressure level of $250 \mathrm{hPa}$, as well as monthly-mean data, were used for the period 1979-2005. The data are available at a horizontal resolution of $0.7^{\circ}$. ERA-Interim is particularly suited to studies of ISS since ISS is explicit within the cloud scheme (Tompkins et al., 2007). This has led to an improved humidity analysis at upper levels, although the analyses show a general dry bias when compared to Atmospheric Infrared Sounder satellite measurements (Lamquin et al., 2009); the ISS frequency in the model climate is lower than observed in the tropics, particularly over the maritime continent, Africa and South America (Tompkins et al., 2007). Forecasts of ice-supersaturated regions produced using the same model version as used to produce the reanalyses also validate well against radiosonde observations and visual observations of contrails (Rädel and Shine, 2010).

In addition to analysing changes to the global frequency and distribution of ISS, regional changes are also analysed. Three subregions of interest are defined: the tropics $\left(30^{\circ} \mathrm{S}-\right.$ $\left.30^{\circ} \mathrm{N}\right)$, $\mathrm{NH}$ mid-latitudes $\left(40-60^{\circ} \mathrm{N}\right)$ and $\mathrm{NH}$ polar regions $\left(70-90^{\circ} \mathrm{N}\right)$. The choice of these three regions is motivated by the present-day distribution of air traffic and projected changes during the 21 st century. Of these three regions, the $\mathrm{NH}$ mid-latitude region currently has the highest proportion of global air traffic (e.g. Wilkerson et al., 2010). Air traffic growth is projected in all three regions, particularly in the tropics; for example, Owen et al. (2010) predict 5 times as much air traffic in some regions in 2050 compared to 2000 for the A2 scenario (their Fig. 2) used in the 2007 IPCC assessment (Riahi et al., 2007), on which the RCP8.5 scenario is based.

\subsection{Definition of ice supersaturation}

Regions of ISS are defined using both relative humidity with respect to ice (RHi) and a temperature threshold. Typically, for persistent contrail formation, the RHi should be greater than $100 \%$, and the temperature should be below a threshold value of $233 \mathrm{~K}$. This temperature threshold is necessary in order to avoid considering regions where mixed-phase or supercooled clouds could form, and is additionally consistent with the threshold temperature for contrail formation at cruise altitudes, defined by the Schmidt-Appleman criterion (e.g. Schumann, 1996); we note that in reality the threshold temperature is somewhat dependent on altitude, humidity, fuel type and engine efficiency (Schumann, 1996). To make it clear that the temperature threshold has been applied, we 
Table 1. Characteristics of the CMIP5 models used in this study. The CISS threshold is the threshold RHi value used in the calculation of the annual-mean, global-mean CISS frequency at $250 \mathrm{hPa}$ in the present-day climate (note a temperature threshold of $233 \mathrm{~K}$ is also applied). The change in CISS frequency (in percentage points) is calculated as the global-mean, annual-mean CISS frequency in the RCP8.5 simulation over the period 2073-2099 minus that in the historical simulation over the period 1979-2005.

\begin{tabular}{|c|c|c|c|c|c|c|}
\hline \multicolumn{2}{|c|}{ Model } & Centre & $\begin{array}{l}\text { Horizontal } \\
\text { resolution }\end{array}$ & $\begin{array}{l}\text { CISS } \\
\text { threshold } \\
(\%)\end{array}$ & $\begin{array}{l}\text { CISS } \\
\text { frequency } \\
1979-2005 \\
(\%)\end{array}$ & $\begin{array}{l}\text { Change in } \\
\text { CISS frequency } \\
\text { (percentage points) }\end{array}$ \\
\hline \multicolumn{2}{|c|}{$\begin{array}{l}\text { ERA-Interim } \\
\text { reanalysis }\end{array}$} & $\begin{array}{l}\text { European Centre for Medium-Range } \\
\text { Weather Forecasts }\end{array}$ & $0.7^{\circ}$ & 92 & 8.1 & - \\
\hline \multirow{5}{*}{$\begin{array}{l}\frac{n}{0} \\
\vdots \\
\vdots \\
n \\
\sum \\
\sum\end{array}$} & EC-EARTH & EC-EARTH consortium & $1.125^{\circ}$ & 98 & 10.1 & -3.6 \\
\hline & GFDL-ESM2G & $\begin{array}{l}\text { NOAA Geophysical Fluid } \\
\text { Dynamics Laboratory }\end{array}$ & $\begin{array}{l}2.0^{\circ} \text { lat, } \\
2.5^{\circ} \text { long }\end{array}$ & 72 & 10.8 & -3.3 \\
\hline & HadGEM2-CC & Met Office Hadley Centre & $\begin{array}{l}1.25^{\circ} \text { lat, } \\
1.875^{\circ} \text { long }\end{array}$ & 78 & 12.1 & -4.9 \\
\hline & MIROC5 & $\begin{array}{l}\text { Atmosphere and Ocean Research Institute } \\
\text { (The University of Tokyo), National Institute } \\
\text { for Environmental Studies, Japan Agency for } \\
\text { Marine-Earth Science and Technology }\end{array}$ & $1.4^{\circ}$ & 93 & 11.1 & -3.5 \\
\hline & MPI-ESM-MR & Max Planck Institute for Meteorology & $1.875^{\circ}$ & 97 & 10.5 & -4.7 \\
\hline
\end{tabular}

refer to cold ISS (CISS) henceforth. We note that climate models, including the CMIP5 models analysed here, often have large temperature biases in their representation of the upper troposphere in the present-day climate. The use of a fixed temperature threshold may therefore lead to an underestimation or overestimation of the amount of CISS, depending on the direction of the bias, in regions where the true temperature is often close to this temperature threshold. The temperature biases of the CMIP5 models used in this study are analysed in Sect. 3.1.

For studies based on model data, it is appropriate to select an RHi threshold below $100 \%$ in order to account for sub-grid-scale variability in the humidity field and the relatively coarse horizontal resolution of the model data in comparison to typical sizes of CISS regions. For example, the horizontal grid spacing of the CMIP5 models used here (Table 1) is of similar size to the mean size of CISS regions, of $150 \mathrm{~km}$, reported by in situ aircraft measurements (Gierens and Spichtinger, 2000). However, we find it problematic to use a single RHi threshold to define CISS at a single level for a set of models that have varying horizontal resolution, model parameterisations and biases. For example, using a RHi threshold of $90 \%$ gives annual-mean, global-mean CISS frequencies ranging from 1 to $19 \%$ (compared to $11 \%$ for ERA-Interim) for the historical period for the five CMIP5 models used here. This vast range makes it difficult to compare the CISS distributions between the models. The model range of CISS frequencies is likely because of different representations of cloud processes and water vapour transport. These lead to distinctly different RHi distributions between the models (Fig. 1); GFDL-ESM2G and HadGEM2-CC have a higher proportion of lower RHi values than ERA-Interim, whereas MPI-ESM-MR has a higher proportion of very high RHi values.

To enable a fairer comparison between the CMIP5 models, instead of using a fixed RHi threshold we chose to use a threshold that varied by model. This is justified since we do not seek to quantify the frequency of CISS in each model for a particular region or time; rather, we are interested in comparing the spatial distribution of CISS between the models and quantifying the change in CISS frequency between the future and historical simulations of the same models. The threshold was defined as follows: for each model, we calculated the cumulative probability distribution of RHi (Fig. 1) using RHi data directly from each model, and found the RHi value corresponding to the 90th percentile of RHi. The resulting model-dependent RHi thresholds are given in Table 1. For ERA-Interim the RHi threshold is $92 \%$, and for the CMIP5 models the thresholds range from $72 \%$ (GFDLESM2G) to $98 \%$ (EC-EARTH).

Using the $233 \mathrm{~K}$ temperature and model-dependent RHi thresholds specified above, the global-mean, annual-mean $250 \mathrm{hPa}$ CISS frequency over the period $1979-2005$ is $8.1 \%$ in ERA-Interim, and varies between 10.1 and $12.1 \%$ in the historical simulations of the CMIP5 models (Table 1). Applying this RHi threshold ensures that the global-mean CISS frequency is close to the "observed" frequency, without constraining the regional distribution of ISS frequency. 


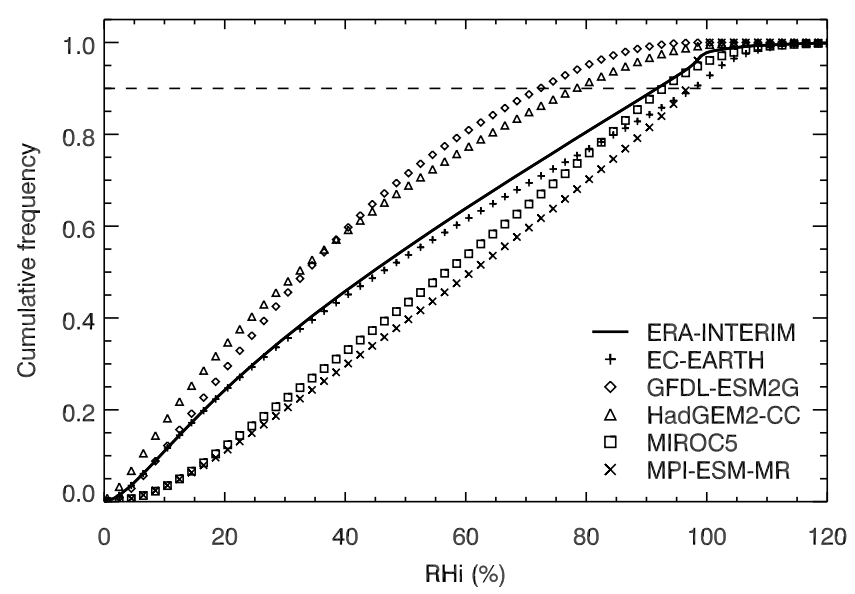

Figure 1. Cumulative frequency distribution of $250 \mathrm{hPa}$ relative humidity with respect to ice for ERA-Interim (solid line) and the CMIP5 models (symbols). Global daily data over the period 19792005 are used. The dashed line marks the 90th percentile of the RHi distribution, used to define the model-dependent RHi threshold for ice-supersaturated regions.

\section{Results}

\subsection{Cold ice supersaturation in the present-day climate}

The annual-mean distribution of CISS at $250 \mathrm{hPa}$ in the present-day climate for the period 1979-2005 is shown for ERA-Interim in Fig. 2a. At this pressure level, there are high frequencies (exceeding 20\%) of cold ice supersaturation over the tropics, although, as previously noted, ERA-Interim is known to underestimate CISS in this region (Tompkins et al., 2007). The distribution of high ISS frequencies in the tropics is not uniform and is linked to regions of deep convection; high frequencies are observed in particular over the northern Indian Ocean and maritime continent and also parts of central Africa, in agreement with in situ aircraft measurements (Luo et al., 2007). Some of the highest frequencies of CISS (exceeding $20 \%$ ) in ERA-Interim are in the Southern Hemisphere polar region, south of $70^{\circ} \mathrm{S}$. These are also observed by satellite measurements (e.g. Gettelman et al., 2006; Lamquin et al., 2012), but the future evolution of these is of little interest to this study because of the lack of air traffic in this region. There are also elevated frequencies in the mid-latitude regions and over Russia. In particular, regions of high frequencies of CISS are found in the North Atlantic and north-west Pacific regions; their location and south-west to north-east tilt suggest they are related to the storm tracks in these regions (e.g. Irvine et al., 2012).

The distribution of CISS in the historical simulations of the CMIP5 models for the same time period is shown in Fig. 2b-f. These can be qualitatively compared to the distribution in ERA-Interim (Fig. 2a) in order to assess the performance of each model in simulating CISS in the presentday climate. (Values, as labelled contours, are also shown

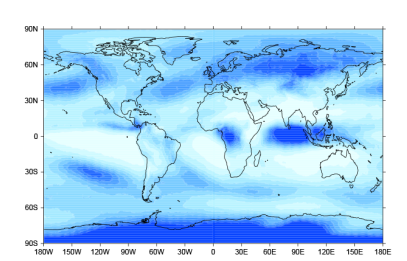

(b)

(c)

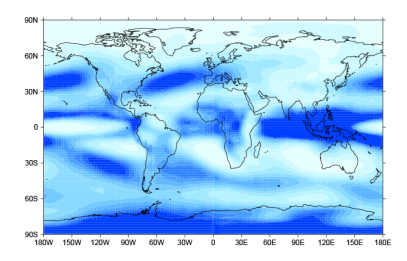

(e)

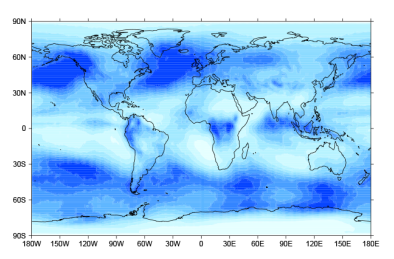

(f)

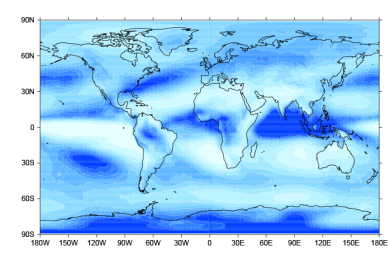

(d)
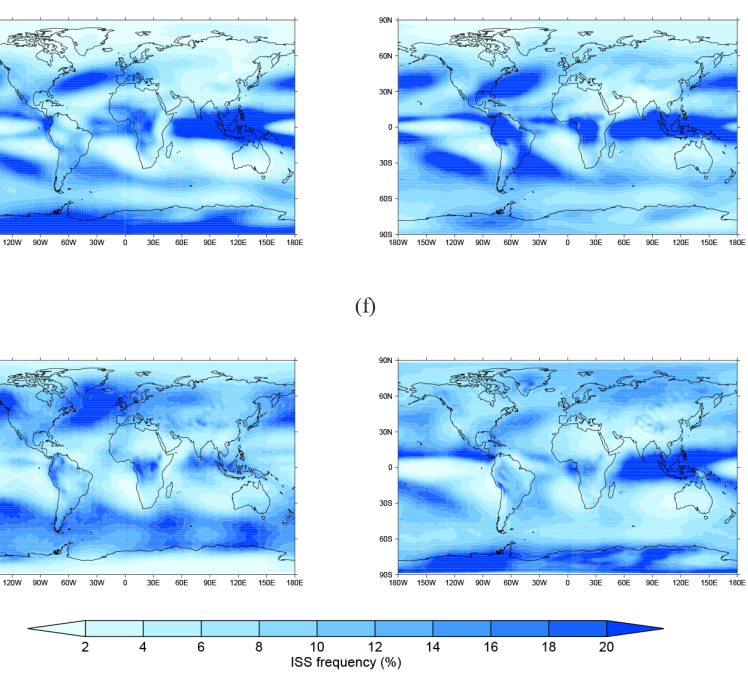

Figure 2. Annual-mean CISS frequency at $250 \mathrm{hPa}$ over the present-day period 1979-2005 for (a) ERA-Interim reanalysis and the CMIP5 models (b) EC-EARTH, (c) GFDL-ESM2G, (d) HadGEM2-CC, (e) MIROC5 and (f) MPI-ESM-MR. The CISS fields for the five CMIP5 models are repeated in Fig. 4 as labelled contours.

as the underlay in Fig. 4.) There are differences in the distribution of CISS between the CMIP5 models, even though the way the RHi threshold for CISS has been defined means that the global-mean, annual-mean CISS frequency in each model is similar. All models qualitatively reproduce the main features of the ERA-Interim CISS distribution although with varying frequencies; all models have high frequencies of CISS in the tropics and in mid-latitude storm tracks. EC-EARTH (Fig. 2b), GFDL-ESM2G (Fig. 2c) and MPIESM-MR (Fig. 2f) also have high CISS frequencies in the Southern Hemisphere polar region (exceeding $20 \%$ in some areas), in similar locations, and with similar frequencies, to ERA-Interim; EC-EARTH and MPI-ESM-MR also have high ISS frequencies over Russia (exceeding $14 \%$ ), in reasonable agreement with ERA-Interim, which are missing from GFDL-ESM2G at this level (where there are large areas at less than 2\%). HadGEM2-CC (Fig. 2d) has somewhat lower frequencies of CISS over Antarctica (less than $8 \%$ in some regions) and Russia at this level (with maxima no more than $8 \%$ ) than ERA-Interim. Of the five CMIP5 models analysed, the MIROC5 model distribution of CISS (Fig. 2e) has 
the largest differences from ERA-Interim outside the tropics: the CISS frequency in the mid-latitudes is the highest of any of the models (exceeding $26 \%$ in the Pacific), while the CISS frequencies in the southern polar region are less than $2 \%$ over large areas.

There are several reasons why we might expect to find differences between the distribution of CISS in ERA-Interim and the CMIP5 models. The use of a single pressure level to analyse CISS is one factor, since regions of CISS are typically shallow and located close to the tropopause (Spichtinger et al., 2003a; Rädel and Shine, 2007). Satellitederived climatologies of ISS frequencies show significant differences in ISS frequency and distribution at different levels in the upper troposphere (e.g. Spichtinger et al., 2003b; Lamquin et al., 2012). Hence any bias in tropopause height in the models, particularly in the mid-latitudes, where the $250 \mathrm{hPa}$ level is often close to the tropopause, would bias the resulting CISS frequencies. Since the CMIP5 data archive retains model data on only a limited number of pressure levels in the upper troposphere, we do not attempt to compute a bias in tropopause height for each model.

An additional reason for the differences between the models in Fig. 2 is that the CMIP5 models exhibit substantial temperature biases at the $250 \mathrm{hPa}$ level when compared to ERA-Interim, although this is ameliorated to some extent (at least at the global-mean level) by the choice of a modeldependent CISS threshold (Table 1 and Fig. 1). Figure 3a, c and e show probability density functions (PDFs) of temperature for ERA-Interim and each CMIP5 model for the three subregions of interest. The size of the temperature bias varies by model and region, but is typically a few kelvin in magnitude, with almost all models and regions biased cold. Since a region is only considered ice-supersaturated if the temperature is below the $233 \mathrm{~K}$ threshold (shown as a dashed line in Fig. 3), a cold bias could lead to an overestimation of ISS in regions where the temperature is often close to this threshold. Figure 3 shows that, for the NH mid-latitude (Fig. 3c) and polar (Fig. 3e) regions, the temperature threshold is at the upper limit of the temperature PDF in the present-day climate, and so the bias will have little impact on CISS frequency. However, in the tropics, the $250 \mathrm{hPa}$ temperature in ERA-Interim is often around the $233 \mathrm{~K}$ threshold, but in the CMIP5 models it is almost always below the threshold in the present-day climate (Fig. 3a), and so could impact the CISS frequency. Additionally, since relative humidity is exponentially related to temperature through the saturation vapour pressure, a cold temperature bias will cause a high relative humidity bias (for the same specific humidity). In the CMIP5 models, however, the cold temperature bias is accompanied by a dry bias in the specific humidity. PDFs of specific humidity (Fig. 3b, d, f) show mean biases of the order of $10^{-2} \mathrm{~g} \mathrm{~kg}^{-1}$ in the tropics and $\mathrm{NH}$ mid-latitude regions, and $10^{-3} \mathrm{~g} \mathrm{~kg}^{-1}$ in the NH polar regions. In all regions, the CMIP5 models typically have a higher proportion of points with low specific humidity than in ERA-Interim, and fewer with high specific humidity in the tail of the distribution.

\subsection{Changes to ice supersaturation over the 21st century}

Changes to the ISS frequency and distribution over the 21st century are now investigated, using the RCP8.5 simulations of the CMIP5 models. The annual-mean, global-mean change in $250 \mathrm{hPa}$ CISS frequency by the end of the 21 st century is shown in Table 1, calculated as the average frequency over the period 2073-2099 minus the average over 19792005 (from the historical simulation). All models predict a decrease in the annual-mean, global-mean CISS frequency by the end of the 21 st century, relative to the present day. The multi-model-mean decrease is substantial, from a presentday value of $11 \%$ to an end-of-century value of $7 \%$. The range of the decrease is 3.3-4.9 percentage points over the individual models. This is a relatively narrow range, given the differences in the spatial distribution of CISS in the models in the present-day climate.

The spatial distribution of the change in $250 \mathrm{hPa}$ CISS frequency due to climate change is shown in Fig. 4 for each of the CMIP5 models, using the same time periods as above. The present-day distribution of ISS in each model is shown by black contours in order to see the relationship between the present-day distribution of ISS and future changes to it. There are several features common to all five models. Firstly, all models predict strong decreases in the frequency of CISS in the tropics; the regions of strongest decrease correlate well with the regions of highest frequency of CISS in the presentday climate. All models show an increase in CISS frequency in both the northern and southern high latitudes, although the size of the change varies between models. The largest differences between the models are found in the mid-latitudes. This is not surprising, given that the $250 \mathrm{hPa}$ level is very close to the tropopause in the mid-latitudes, as previously discussed, and so the CISS frequency will be very sensitive to small changes in tropopause height. CISS in the midlatitudes is often linked to the storm track regions; maxima in CISS frequency coincide with the location and orientation of the storm track in all major basins. In the annual mean, all the models studied predict a small northward shift in jet stream location over the North Atlantic (Irvine et al., 2015), for example, but the change to ISS frequency in the models in this region varies. For example, GFDL-ESM2G (Fig. 4b) suggests a northward shift in the CISS frequency maxima in both North Atlantic and Pacific storm track regions, whereas for most other models the change appears to be a decrease in the strength of the CISS maxima in these regions.

Figure 5 shows a time series of the multi-model-mean change in CISS frequency, from 1979 to 2100 , i.e. from the historical period through the RCP8.5 period. The change in frequency is calculated separately for each CMIP5 model as the annual-mean frequency in each year minus the 1979- 
(a)

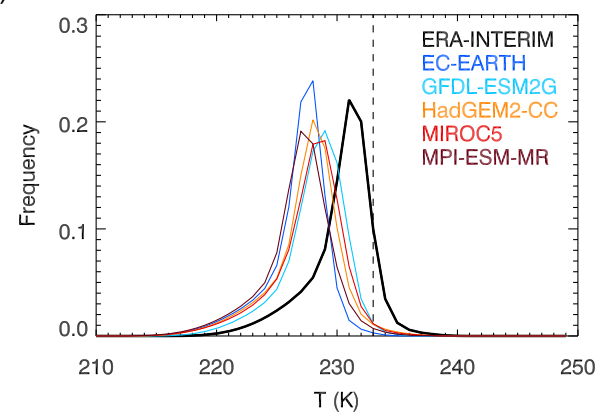

(c)

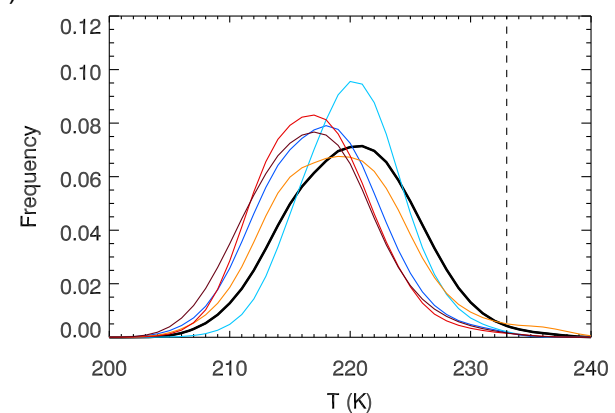

(e)

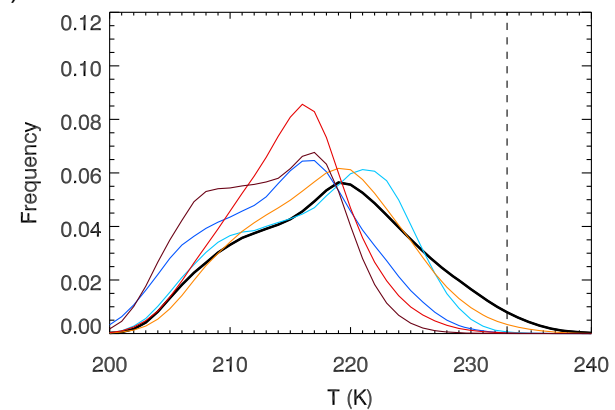

(b)

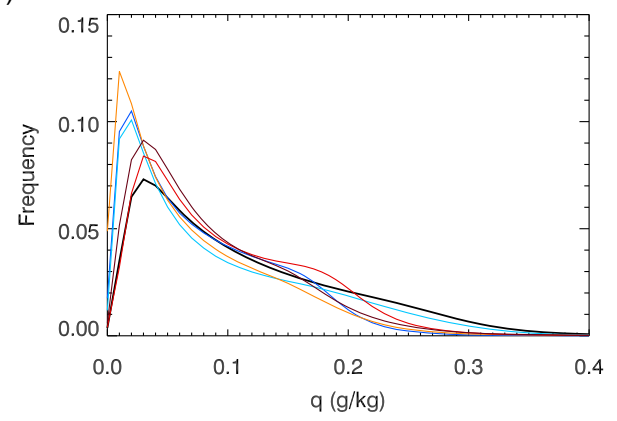

(d)

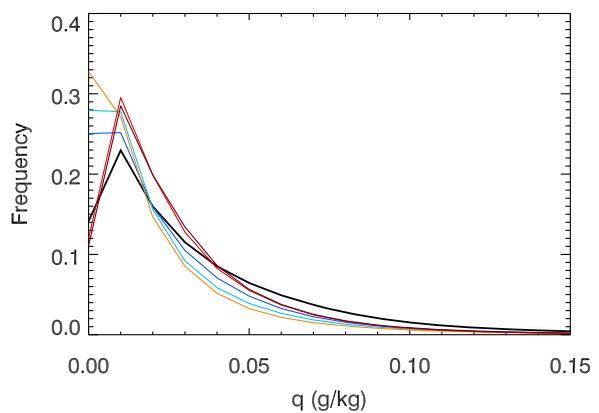

(f)

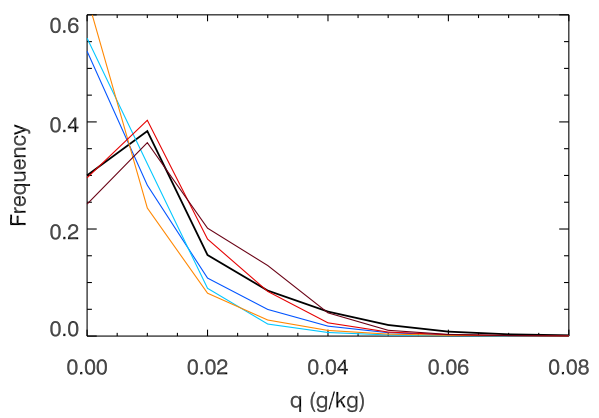

Figure 3. PDFs of temperature, $T$ (left column), and specific humidity, $q$ (right column), at $250 \mathrm{hPa}$ in the present-day climate (1979-2005) in three regions - $(\mathbf{a}, \mathbf{b})$ the tropics, $(\mathbf{c}, \mathbf{d})$ the NH mid-latitudes and $(\mathbf{e}, \mathbf{f})$ the NH polar regions - shown for ERA-Interim reanalysis (black line) and CMIP5 models EC-EARTH (dark blue), GFDL-ESM2G (light blue), HadGEM2-CC (orange), MIROC5 (red) and MPI-ESM-MR (dark red). The $233 \mathrm{~K}$ temperature threshold is marked by the dashed line on panels (a), (c) and (e).

2005 average. The individual time series are then averaged together to provide a multi-model mean (plotted). There is considerable inter-annual variability in the CISS frequency, particularly on seasonal timescales, and so the multi-modelmean time series has been smoothed with a 10-year running mean to allow the long-term trends in the multi-model mean to be more clearly seen. The time series are shown separately for each region, and the mean changes in that region from the historical period to mid-century (2030-2056) and latecentury (2073-2099) periods are given separately for each model as well as the multi-model mean in Table 2.

For the $\mathrm{NH}$ polar regions, the time series shows an increase in CISS frequency through the 21st century. By 2100, the changes in the smoothed time series are clearly larger than any internal variability. The rate of increase is faster over the second half of the 21st century than the first half; the multi-model-mean increase in annual-mean CISS frequency is 1.7 percentage points (range 0.9 to 2.2 percentage points, Table 2 ) by mid-century and 4.9 percentage points (range 2.8 to 6.2 percentage points) by the end of the century. There is a strong seasonality to the changes; the largest changes are in the autumn (September, October and November) and smallest in the spring (March, April and May) (not shown). At these latitudes, $250 \mathrm{hPa}$ is certainly in the stratosphere, and the water vapour content of the air is very small, as shown by the small values of specific humidities in the PDFs in Fig. 3f. Any contrails forming in this region may have small optical depths such that their impact on climate is lower than contrails formed in other regions with higher water vapour contents. Thus the increase in CISS frequency shown here 
(a)

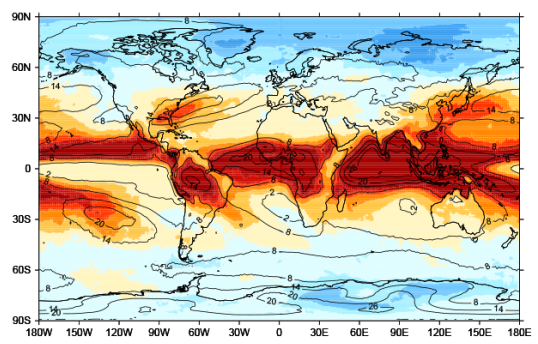

(c)

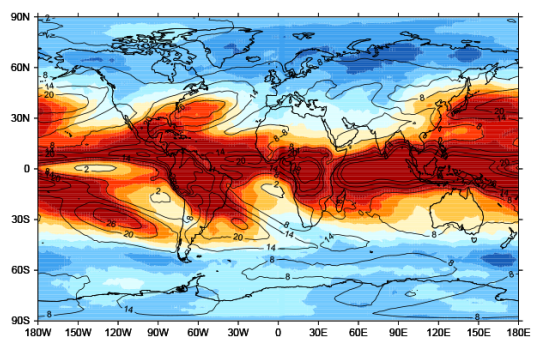

(b)

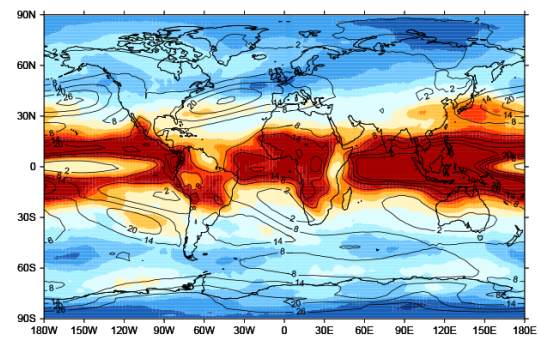

(d)

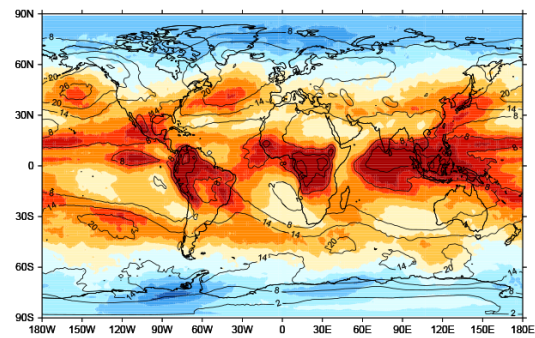

(e)
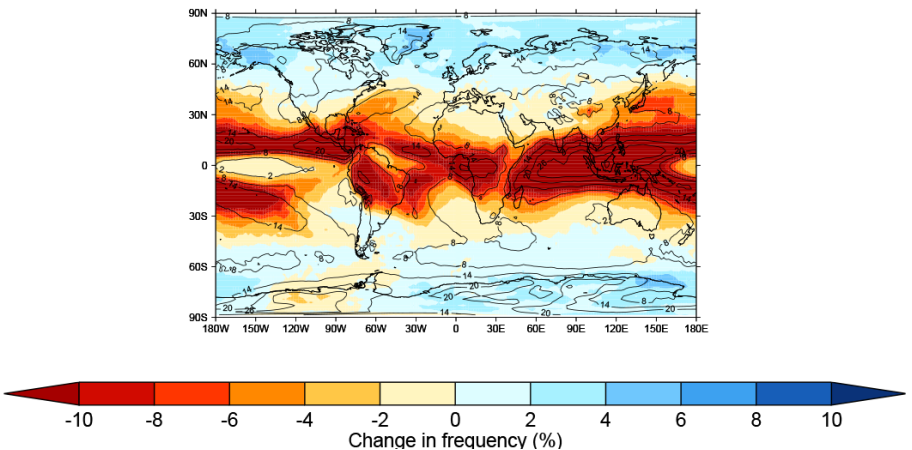

Figure 4. Change in mean CISS frequency at $250 \mathrm{hPa}$ (colours) in percentage points between the RCP8.5 simulation (average over 20732099) and historical simulation (average over 1979-2005) for the CMIP5 models (a) EC-EARTH, (b) GFDL-ESM2G, (c) HadGEM2-CC, (d) MIROC5 and (e) MPI-ESM-MR. The mean CISS frequency (in \%) in each model over the historical period 1979-2005 is overlaid (black contours - starting at $2 \%$, with a $6 \%$ contour interval).

may be less significant in terms of persistent-contrail climate impact than for the other regions studied.

In the $\mathrm{NH}$ mid-latitude region there is little change in the annual-mean CISS frequency over the 21 st century (Fig. 5). The multi-model-mean changes by mid-century and the end of century are comparable, with increases of 0.7 and 0.9 percentage points respectively. Moreover, there is some disagreement between the models on the sign of the change. MIROC5 predicts small decreases in CISS frequency by both the mid-century and end-of-century time periods. ECEARTH and MPI-ESM-MR predict no change by the end of the 21 st century, whereas GFDL-ESM2G and HadGEM2-
CC predict small increases. This spread in model behaviour is likely linked to the different jet stream and tropopause height climatologies in the models, since in this region $250 \mathrm{hPa}$ is often close to the tropopause, and regions of CISS are often associated with the position of the jet stream in the model. There is some seasonality to the CISS changes shown; the multi-model mean shows an increase of around 3 percentage points in winter (December, January and February - DJF), and a decrease of around 2 percentage points in summer (June, July and August - JJA) by the end of the 21st century (Fig. 5). At this altitude, the CISS frequency is higher in summer than winter in the reanalysis data (not shown). 
Table 2. Changes to the annual-mean frequency of CISS at $250 \mathrm{hPa}$ from the RCP 8.5 simulation minus the historical simulation, for the subregions of interest. The change is shown for two time periods: the middle and end of the 21 st century.

\begin{tabular}{|c|c|c|c|c|c|c|}
\hline \multirow[t]{3}{*}{ Model } & \multicolumn{6}{|c|}{$\begin{array}{l}\text { Change in CISS frequency } \\
\text { (percentage points) }\end{array}$} \\
\hline & \multicolumn{3}{|c|}{$(2030-2056)-(1979-2005)$} & \multicolumn{3}{|c|}{$(2073-2099)-(1979-2005)$} \\
\hline & Tropics & NH mid-lats & NH polar & Tropics & NH mid-lats & $\mathrm{NH}$ polar \\
\hline EC-EARTH & -2.6 & 0.4 & 1.8 & -7.6 & 0.2 & 4.5 \\
\hline GFDL-ESM2G & -2.6 & 1.5 & 1.6 & -9.5 & 3.8 & 6.0 \\
\hline HadGEM2-CC & -5.6 & 1.8 & 2.2 & -11.5 & 2.4 & 6.2 \\
\hline MIROC5 & -2.7 & -0.5 & 2.0 & -6.1 & -1.8 & 5.0 \\
\hline MPI-ESM-MR & -3.2 & 0.2 & 0.9 & -9.2 & 0.1 & 2.8 \\
\hline Multi-model mean & -3.3 & 0.7 & 1.7 & -8.8 & -0.9 & 4.9 \\
\hline
\end{tabular}

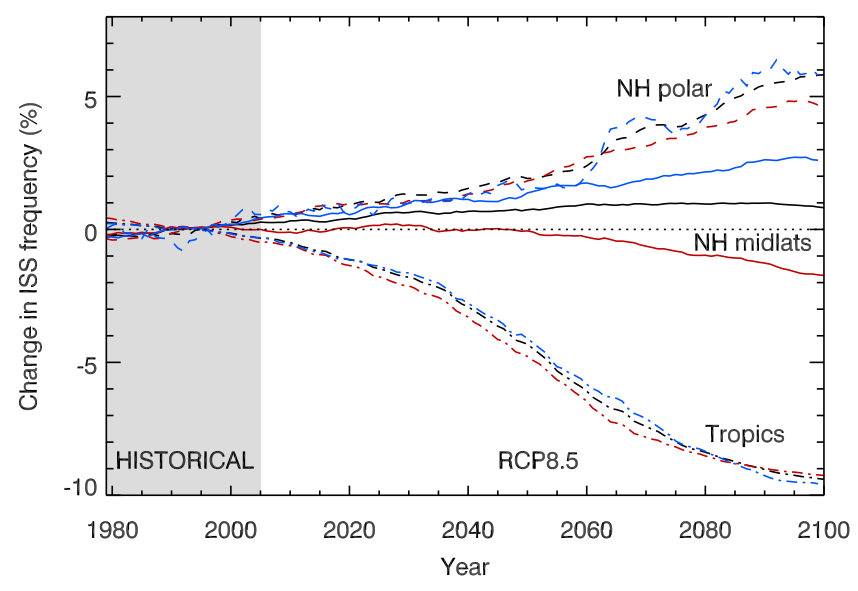

Figure 5. Time series of the multi-model-mean change in CISS frequency (in percentage points) at $250 \mathrm{hPa}$ from 1979 to 2099 , calculated for each year as the mean CISS frequency minus the 1979-2005 average (the historical period, shown by grey shading). The change is calculated separately for the tropics (dashed-dotted lines), NH mid-latitudes (solid lines) and NH polar (dashed lines) regions, for the annual (black lines), DJF (blue lines) and JJA (red lines) mean changes. The changes are calculated separately for each CMIP5 model and averaged to provide a multi-model mean; a 10year running mean has been applied to each time series before plotting.

In the tropics there is a strong decrease in annual-mean CISS frequency throughout the 21 st century. As in the polar regions, by 2100 , the changes in the smoothed time series are clearly larger than any internal variability. The decrease is strongest through the middle of the century, and begins to level off by 2080 . The multi-model-mean change is a decrease of 3.3 percentage points by mid-century (range 2.6 to 5.6 percentage points, Table 2 ), and 8.8 percentage points by the end of the century (range 6.1 to 11.5 percentage points). Given the nature of CISS regions in the tropics, and that we are averaging over both Northern and Southern Hemisphere portions of the tropics, it is unsurprising that there is little

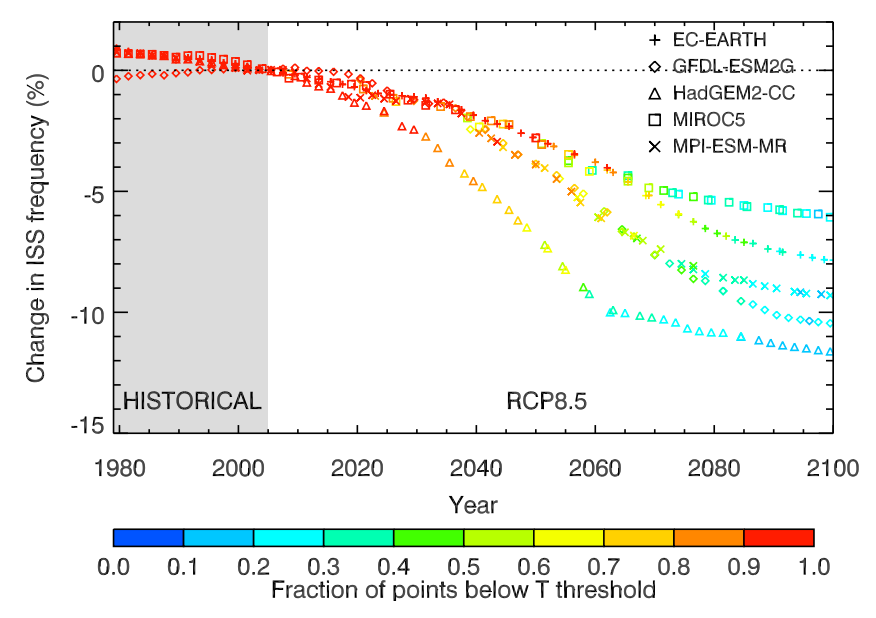

Figure 6. Time series of the change in $250 \mathrm{hPa}$ CISS frequency (in percentage points) in the tropics in the CMIP5 models (symbols) from 1979 to 2099, calculated for each year as the annual-mean CISS frequency minus the 1979-2005 average (the historical period, shown by grey shading). The colour of the points shows the fraction of points in the tropics which are below the $233 \mathrm{~K}$ temperature threshold for CISS. A 10-year running mean has been applied to each time series before plotting.

seasonality to this change. The main factor driving the large decrease in CISS frequency in the tropics is temperature. Figure 6 shows a time series of average change in tropical CISS frequency for each model, with colours used to indicate the fraction of all tropical points in each model which are below the $233 \mathrm{~K}$ temperature threshold used to define a CISS region. During the historical period this is always above 0.9, and therefore it is almost always sufficiently cold for contrail formation, so that the limiting factor determining the CISS frequency would be the humidity. This fraction begins to decrease in the 2030s and by 2080 it has dropped below 0.2; this low fraction means that, regardless of the humidity, over most of the tropics it is too warm to meet the definition of a CISS region. This explains the sharp decrease in CISS fre- 
quency predicted by the models. Note that the changes during the historical period, a decrease in CISS frequency, are very small in comparison to the predicted changes over the $21 \mathrm{st}$ century.

Since the ISS changes without application of the temperature threshold are also of interest, beyond the context of contrail formation, we briefly comment on the ISS trends. Since the tropics dominate the global mean, and the tropical CISS results are strongly influenced by the temperature threshold, the global-mean ISS trends are expected to be less strong than their CISS counterparts. The global-mean values (in percentage points) corresponding to the time period in Table 1 are -1.5 (EC-EARTH), +4.9 (GFDL-ESM2G), -0.004 (HadGEM2-CC), -1.5 (MIROC5) and -1.2 (MPIESM-MR). All models show an increase in polar regions, albeit less strong than indicated for CISS in Table 2, while all models show a decrease in the tropics, with the exception of GFDL-ESM2G, which shows an increase and hence strongly influences the global-mean response in that model. As will be discussed in Sect. 3.3, the GFDL-ESM2G model has quite a different predicted relative humidity response in the tropical upper troposphere compared to the other models discussed here, with increases near $250 \mathrm{hPa}$.

\subsection{Extension of results to multiple levels}

Our analysis of CISS regions has so far concentrated on the $250 \mathrm{hPa}$ level, for which daily-mean data are available. In order to assess whether the changes in CISS frequency over the $21 \mathrm{st}$ century can be generalised to levels other than $250 \mathrm{hPa}$, monthly-mean data are analysed. Given the relatively smallscale and short-timescale nature of CISS regions, it would not be particularly meaningful to try to define regions of CISS using monthly-mean data. Instead, we use the annualmean zonal-mean differences between the RCP8.5 and historical simulations of the CMIP5 models to analyse the vertical structure of changes in mean RHi and temperature. These are shown separately for each CMIP5 model as the average over 2073-2099 minus the average over 1979-2005, in Fig. 7. The latitudinal bounds of the tropical, NH midlatitudes and $\mathrm{NH}$ polar regions are also given, along with the range of typical cruise altitudes of commercial aircraft (approximately $300-200 \mathrm{hPa}$ ).

There is generally good agreement on the vertical structure of zonal-mean temperature and relative humidity changes between the models. For the NH polar regions, the models agree on an increase in mean relative humidity over the altitude range of interest, which suggests that the increase in CISS frequency predicted in this region at $250 \mathrm{hPa}$ will also occur at other cruise altitudes. Mean temperature changes in this region are irrelevant for CISS frequency, since the temperatures at flight level are well below the $233 \mathrm{~K}$ threshold. For the NH mid-latitude region, there is less agreement between models; the mean changes are more dependent on altitude and latitude. However, all models agree on an increase in relative humidity at altitudes above $250 \mathrm{hPa}$, with the largest changes at the highest flight levels. It is possible that there will be a decrease in CISS regions at low mid-latitudes and flight levels, from a combination of the decrease in relative humidity and increase in temperature (which will increase the number of days where the temperature is above the $233 \mathrm{~K}$ threshold). In the tropics, all models except GFDL-ESM2G (Fig. 7b) predict a decrease in mean relative humidity; this decrease in relative humidity has been found by many previous studies (e.g. Lorenz and DeWeaver, 2007; Wright et al., 2010; Sherwood et al., 2010) and is considered a robust signal of climate change. All models predict a strong warming over the altitude range of interest in the tropics; most importantly, this has the effect of pushing temperatures above the $233 \mathrm{~K}$ threshold and so reducing the potential for contrail formation, regardless of any changes in relative humidity. This effect is strongest at the $250 \mathrm{hPa}$ level in the models, but all levels show some reduction. The effect is smaller at higher altitudes, where temperatures are lower and the warming is not sufficient to result in temperatures above the $233 \mathrm{~K}$ threshold. At lower altitudes, where it is warmer, in the present-day climate much of the temperature PDF is already above the $233 \mathrm{~K}$ threshold, so any warming has a smaller effect on the CISS frequency.

\section{Conclusions}

The evolution of meteorological conditions controlling persistent contrail formation during the 21 st century is investigated. Specifically, the frequency and distribution of cold ice-supersaturated regions are analysed in simulations from a selection of models in the CMIP5 multi-model archive, using a model-dependent RHi threshold defined using the cumulative probability distribution of RHi in each model.

The present-day simulations from the CMIP5 models qualitatively reproduce the main features of the CISS distribution seen in ERA-Interim reanalysis data: high frequencies of CISS in the tropical regions, mid-latitude storm tracks, and most models also simulate high frequencies in the southern high-latitude regions. At the $250 \mathrm{hPa}$ level analysed, all models have cold biases of a few kelvin in the tropics. This is particularly significant as in this region observed temperatures are close to the temperature threshold for CISS; as a result, CISS frequencies in the tropics may be overestimated for the present-day climate by the CMIP5 models.

To analyse the impact of climate change on CISS frequency, RCP8.5 simulations were used. This scenario has the highest greenhouse gas concentrations and therefore largest temperature changes of the different scenarios considered by the 2013 IPCC report. Globally, the CMIP5 models predict a decrease in CISS frequency by the end of the 21 st century, of average 4 percentage points (a decrease of about one-third of the present-day value) over the models analysed here. However, this change is not uniform globally, and both the sign 
(a)

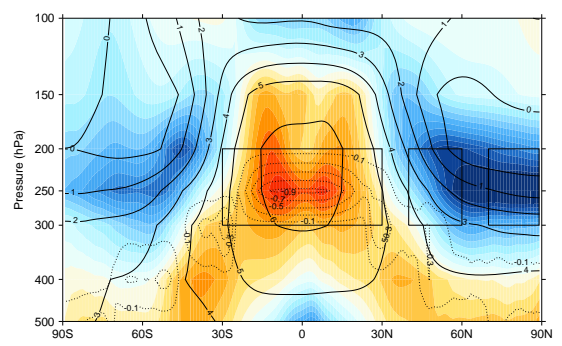

(c)

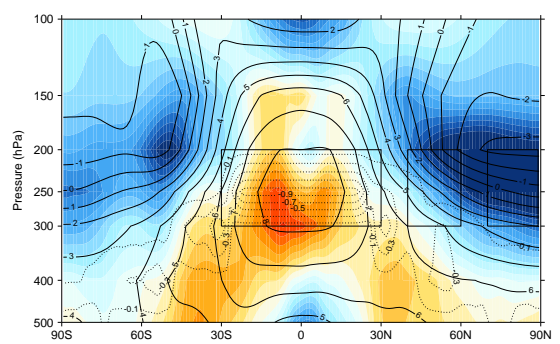

(b)

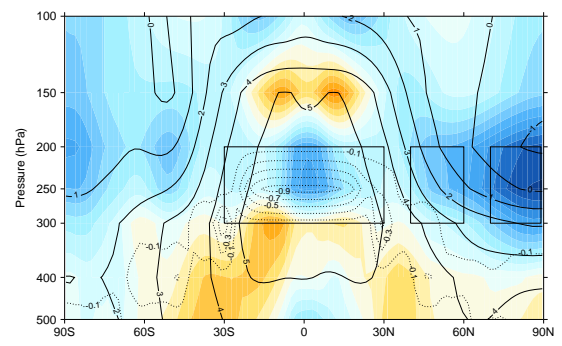

(d)

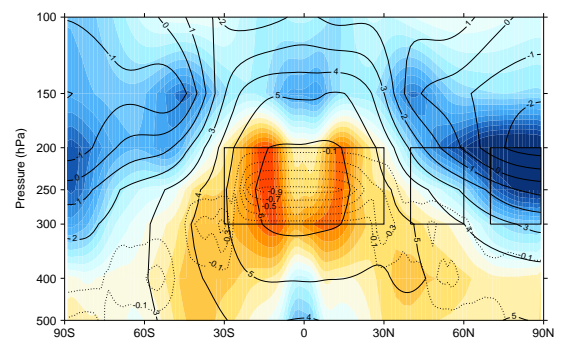

(e)
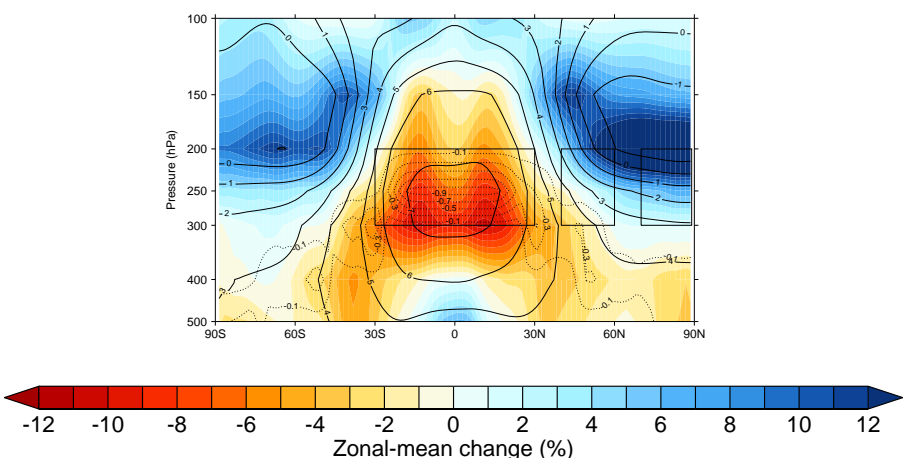

Figure 7. Zonal-mean change in annual-mean RHi (colours), temperature (solid black lines) and fraction of points below the $233 \mathrm{~K}$ temperature threshold (dotted black lines) as a function of pressure for the CMIP5 models (a) EC-EARTH, (b) GFDL-ESM2G, (c) HadGEM2-CC, (d) MIROC5 and (e) MPI-ESM-MR. The changes are calculated using monthly-mean data, as the average over 2073-2099 (RCP8.5 simulation) minus the average over 1979-2005 (historical simulation). The subregions of particular interest are highlighted by black boxes: the tropics, Northern Hemisphere mid-latitudes and Northern Hemisphere polar regions. The vertical range of these boxes is $200-300 \mathrm{hPa}$, spanning the range of typical cruise altitudes for commercial aircraft.

and magnitude of the change in CISS vary by region. The largest contribution to the global-mean decrease is the strong decrease in CISS frequency in the tropics, of 8.8 percentage points in the multi-model mean by the end of the $21 \mathrm{st}$ century. The rate of decrease is strongest in the mid-century, and levels off by the later part of the century. The decrease in CISS frequency is mainly due to the strong warming at the $250 \mathrm{hPa}$ level, which shifts the temperature PDF from below the $233 \mathrm{~K}$ temperature threshold to above it. There is less consensus between the models on the sign and magnitude of the change in the $\mathrm{NH}$ mid-latitudes at the $250 \mathrm{hPa}$ level. The multi-model-mean, annual-mean change is around 1 percentage point by 2100 , and seasonally dependent; models show small increases in CISS frequency in winter and decreases in summer. The models agree on an increase in CISS frequency over the NH polar regions in all seasons, reaching approximately 5 percentage points by 2100 . The results are broadly consistent with those of Marquart et al. (2003), where the focus was on predicting changes in contrail cover for specified distributions of air traffic growth, rather than the frequency 
of CISS. In their simulations, the impact of climate change reduces the 2050 contrail cover by 20 percentage points compared to the case with no climate change, with that decrease concentrated in the tropics.

The CMIP5 zonal-mean monthly-mean relative humidity and temperature projections suggest that the changes projected at the $250 \mathrm{hPa}$ level are applicable to other cruise altitudes, perhaps with the exception of the NH mid-latitudes, where the sign of any change in CISS frequency is more dependent on latitude and altitude. In the tropics, the largest change in the CMIP5 models is at $250 \mathrm{hPa}$, which is in the middle of the range of permitted cruise altitudes. However, since the models have a cold bias, relative to the reanalyses, the level at which the maximum change is seen may actually be higher than this.

The projected changes to ISS frequency over the 21 st century have implications for contrail cover, and consequently contrail climate impact. Persistent contrails form when aircraft fly through the CISS regions analysed here; making projections of actual contrail cover for the 21 st century would require combining the climate model data with estimates of the amount and distribution of air traffic throughout this time period of the climate model simulations, as well as accounting for improvements to aircraft engine technology. Here we provide a discussion of the possible impact of the CISS changes on contrail cover, given projections of air traffic demand and increasing aircraft engine efficiency. In the NH mid-latitudes, where there is already a high volume of air traffic, climate models predict small increases in CISS frequency, particularly in winter. This suggests that there could be small increases in contrail cover from the combination of increased CISS frequency and increased air traffic. Increases in engine efficiency are likely to have only minor impacts on contrail cover in this region since temperatures are normally well below those required for contrail formation. In the tropics, the reduction in CISS frequency is in opposition to the predicted growth in aviation and increase in engine efficiency. It seems likely, however, that a factor of 2-5 increase in air traffic from 2000 to 2050 (Owen et al., 2010) along with an increase in engine efficiency will outweigh the few percentage point decrease in CISS frequency shown here, leading to an increase in contrail cover. In the $\mathrm{NH}$ polar regions, the situation is similar to the $\mathrm{NH}$ mid-latitudes, but with more confidence in larger increases in CISS frequency due to climate change. The predicted increases in CISS frequency presented here, as well as a possible factor of 2 increase in air traffic (Owen et al., 2010), suggest an increase in contrail cover. The climate significance of this is less obvious, since any contrails formed at high latitudes are likely to be very thin, and the level of air traffic is likely to remain far below that of the mid-latitude or tropical regions. Overall, global contrail cover seems likely to increase over the 21st century, with climate change acting to increase contrail cover in the mid-latitude and polar regions and constraining changes in contrail cover in the tropics. In time, improvement in the global observing system may allow a robust evaluation of the model-derived humidity trends, which would impact on the confidence with which those trends can be viewed.

Acknowledgements. This work was supported by the Natural Environment Research Council, grant NE/J021113/1. We thank Brian Hoskins and Jake Gristey for useful discussions during this work. We acknowledge the World Climate Research Programme's Working Group on Coupled Modelling, which is responsible for CMIP, and we thank the climate modelling groups for producing and making available their model output. For CMIP the U.S. Department of Energy's Program for Climate Model Diagnosis and Intercomparison provides coordinating support and led development of software infrastructure in partnership with the Global Organization for Earth System Science Portals. The reviewers are thanked for many helpful comments.

Edited by: V. Lucarini

\section{References}

Burkhardt, U., Kärcher, B., Ponater, M., Gierens, K., and Gettelman, A.: Contrail cirrus supporting areas in model and observations, Geophys. Res. Lett., 35, L16808, doi:10.1029/2008GL034056, 2008.

Collins, W. J., Bellouin, N., Doutriaux-Boucher, M., Gedney, N., Halloran, P., Hinton, T., Hughes, J., Jones, C. D., Joshi, M., Liddicoat, S., Martin, G., O'Connor, F., Rae, J., Senior, C., Sitch, S., Totterdell, I., Wiltshire, A., and Woodward, S: Development and evaluation of an Earth-system model - HadGEM2, Geosci. Model Dev., 4, 1051-1075, doi:10.5194/gmd-4-10512011, 2011.

Davini, P. and Cagnazzo, C.: On the misinterpretation of the north Atlantic oscillation in CMIP5 models, Clim. Dynam., 43, 14971511, doi:10.1007/s00382-013-1970-y, 2013.

Dee, D. P., Uppala, S. M., Simmons, A. J., Berrisford, P., Poli, P., Kobayashi, S., Andrae, U., Balmaseda, M. A., Balsamo, G., Bauer, P., Bechtold, P., Beljaars, A. C. M., van de Berg, L., Bidlot, J., Bormann, N., Delsol, C., Dragani, R., Fuentes, M., Geer, A. J., Haimberger, L., Healy, S. B., Hersbach, H., Hólm, E. V., Isaksen, L., Kållberg, P., Köhler, M., Matricardi, M., McNally, A. P., Monge-Sanz, B. M., Morcrette, J- J., Park, B- K., Peubey, C., de Rosnay, P., Tavolato, C., Thépaut, J- N., and Vitart, F.: The ERA-Interim reanalysis: configuration and performance of the data assimilation system, Q. J. Roy. Meteor. Soc., 13, 553-597, 2011.

Deuber, O., Matthes, S., Sausen, R., Ponater, M., and Ling, L.: A physical metric-based framework for evaluating the climate trade-off between $\mathrm{CO}_{2}$ and contrails - the case of lowering flight trajectories, Environ. Sci. Policy, 25, 176-185, doi:10.1016/j.envsci.2012.10.004, 2013.

Dunne, J. P., John, J. G., Adcroft, A. J., Griffies, S. M., Hallberg, R. W., Shevliakova, E., Stouffer, R. J., Cooke, W., Dunne, K. A., Harrison, M. J., Krasting, J. P., Malyshev, S. L., Milly, P. C. D., Phillipps, P. J., Sentman, L. T., Samuels, B. L., Spelman, M. J., Winton, M., Wittenberg, A. T., and Zadeh, N.: GFDL's ESM2 global coupled climate-carbon earth system models, part I, phys- 
ical formulation and baseline simulation characteristics, J. Climate, 25, 6646-6665, doi:10.1175/JCLI-D-11-00560.1, 2012.

Fichter, C., Marquart, C., Sausen, R., and Lee, D. S.: The impact of cruise altitude on contrails and related radiative forcing, Meteorol. Z., 14, 563-572, 2005.

Gettelman, A., Fetzer, E. J., Eldering, A., and Irion, F. W.: The global distribution of supersaturation in the upper troposphere from the Atmospheric Infrared Sounder, J. Climate, 19, 60896103, 2006.

Gierens, K. and Brinkop. S.: Dynamical characteristics of ice supersaturated regions, Atmos. Chem. Phys., 12, 11933-11942, doi:10.5194/acp-12-11933-2012, 2012.

Gierens, K. and Spichtinger, P.: On the size distribution of icesupersaturated regions in the upper troposphere and lowermost stratosphere, Ann. Geophys., 18, 499-504, doi:10.1007/s00585000-0499-7, 2000.

Gierens, K., Sausen, R., and Schumann, U.: A diagnostic study of the global distribution of contrails, Part II: Future air traffic scenarios, Theor. Appl. Climatol., 63, 1-9, 1999.

Gierens, K., Lim, L., and Eleftheratos, K.: A review of various strategies for contrail avoidance, Open Atmos. Sci. J., 2, 1-7, 2008.

Haglind, F.: Potential of lowering the contrail formation of aircraft exhausts by engine re-design, Aerosp. Sci. Technol., 12, 490497, 2008.

Hazeleger, W., Severijns, C., Semmler, T., Ştefănescu, S., Yang, S., Wang, X., Wyser, K., Dutra, E., Baldasano, J. M., Bintanja, R., Bougeault, P., Caballero, R., Ekman, A. M. L., Christensen, J. H., van den Hurk, B., Jimenez, P., Jones, C., Kållberg, P., Koenigk, T., McGrath, R., Miranda, P., Van Noije, T., Palmer, T., Parodi, J. A., Schmith, T., Selten, F., Storelvmo, T., Sterl, A., Tapamo, H., Vancoppenolle, M., Viterbo, P., and Willén, U.: EC-Earth: a seamless earth-system prediction approach in action, B. Am. Meteorol. Soc., 91, 1357-1363, 2010.

Hazeleger, W., Wang, X., Severijns, C., Stefanescu, S., Bintanja, R., Sterl, A., Wyser, K., Semmler, T., Yang, S., van den Hurk, B., van Noije, T., van der Linden, E., and van der Wiel, K.: EC-EARTH V2.2: description and validation of a new seamless earth system prediction model, Clim. Dynam., 39, 2611-2629, doi:10.1007/s00382-011-1228-5, 2012.

Immler, F., Treffeisen, R., Engelbart, D., Krüger, K., and Schrems, O.: Cirrus, contrails, and ice supersaturated regions in high pressure systems at northern mid latitudes, Atmos. Chem. Phys., 8, 1689-1699, doi:10.5194/acp-8-1689-2008, 2008.

IPCC: Climate Change 2013: The Physical Science Basis. Contribution of Working Group I to the Fifth Assessment Report of the Intergovernmental Panel on Climate Change, edited by: Stocker, T. F., Qin, D., Plattner, G.-K., Tignor, M., Allen, S. K., Boschung, J., Nauels, A., Xia, Y., Bex, V. and Midgley, P. M., Cambridge University Press, Cambridge, UK and New York, 1535 pp., doi:10.1017/CBO9781107415324, 2013.

Irvine, E. A., Hoskins, B. J., and Shine, K. P.: The dependence of contrail formation on the weather pattern and altitude in the north Atlantic, Geophys. Res. Lett., 39, L12802, doi:10.1029/2012GL051909, 2012.

Irvine, E. A., Hoskins, B. J., and Shine, K. P.: A Lagrangian analysis of ice-supersaturated air over the North Atlantic, J. Geophys. Res., 119, 90-100, doi:10.1002/2013JD020251, 2014a.
Irvine, E. A., Hoskins, B. J., and Shine, K. P.: A simple framework for assessing the trade-off between the climate impact of aviation dioxide emissions and contrails for a single flight, Environ. Res. Lett., 9, 064021, doi:10.1088/1748-9326/9/6/064021, 2014 b.

Irvine, E. A., Shine, K. P., and Stringer, M. A.: What are the implications of climate change for trans-Atlantic aircraft routing and flight time?, Transport. Res. D-Tr. E., in review, 2015.

Kästner, M., Meyer, R., and Wendling, P.: Influence of weather conditions on the distribution of persistent contrails, Meteorol. Appl., 6, 261-271, doi:10.1017/S1350482799001231, 1999.

Lamquin, N., Gierens, K., Stubenrauch, C. J., and Chatterjee, R.: Evaluation of upper tropospheric humidity forecasts from ECMWF using AIRS and CALIPSO data, Atmos. Chem. Phys., 9, 1779-1793, doi:10.5194/acp-9-1779-2009, 2009.

Lamquin, N., Stubenrauch, C. J., Gierens, K., Burkhardt, U., and Smit, H.: A global climatology of upper-tropospheric ice supersaturation occurrence inferred from the Atmospheric Infrared Sounder calibrated by MOZAIC, Atmos. Chem. Phys., 12, 381405, doi:10.5194/acp-12-381-2012, 2012.

Lee, D. S., Fahey, D. W., Forster, P. M., Newton, P. J., Wit, R. C. N., Lim, L. L., Owen, B., and Sausen, R.: Aviation and global climate change in the 21 st century, Atmos. Environ., 43, 35203537, 2009.

Lee, Y.-Y. and Black, R. X.: Boreal winter low-frequency variability in CMIP5 models, J. Geophys. Res.-Atmos., 118, 6891-6904, doi:10.1002/jgrd.50493, 2013.

Lorenz, D. J. and DeWeaver, E. T.: The response of the extratropical hydrological cycle to global warming, J. Climate, 20, 34703484, 2007.

Luo, Z., Kley, D., Johnson, R. H., and Smit, H.: Ten years of measurements of tropical upper-tropospheric water by MOZAIC, Part I: Climatology, variability, transport and relation to deep convection, J. Climate, 20, 418-435, 2007.

Mannstein, H., Spichtinger, P., and Gierens, K.: A note on how to avoid contrail cirrus, Transport. Res. D-Tr. E., 10, 421-426, 2005.

Marquart, S., Ponater, M., Mager, F., and Sausen, R.: Future development of contrail cover, optical depth, and radiative forcing: impacts of increasing air traffic and climate change, J. Climate, 16, 2890-2904, 2003.

Martin, G. M., Bellouin, N., Collins, W. J., Culverwell, I. D., Halloran, P. R., Hardiman, S. C., Hinton, T. J., Jones, C. D., McDonald, R. E., McLaren, A. J., O’Connor, F. M., Roberts, M. J., Rodriguez, J. M., Woodward, S., Best, M. J., Brooks, M. E., Brown, A. R., Butchart, N., Dearden, C., Derbyshire, S. H., Dharssi, I., Doutriaux-Boucher, M., Edwards, J. M., Falloon, P. D., Gedney, N., Gray, L. J., Hewitt, H. T., Hobson, M., Huddleston, M. R., Hughes, J., Ineson, S., Ingram, W. J., James, P. M., Johns, T. C., Johnson, C. E., Jones, A., Jones, C. P., Joshi, M. M., Keen, A. B., Liddicoat, S., Lock, A. P., Maidens, A. V., Manners, J. C., Milton, S. F., Rae, J. G. L., Ridley, J. K., Sellar, A., Senior, C. A., Totterdell, I. J., Verhoef, A., Vidale, P. L., and Wiltshire, A.: The HadGEM2 family of Met Office Unified Model climate configurations, Geosci. Model Dev., 4, 723-757, doi:10.5194/gmd-4723-2011, 2011.

Minnis, P., Ayers, J. K., Palikonda, R., and Phan, D.: Contrails, cirrus trends and climate, J. Climate, 17, 1671-1685, 2004. 
Owen, B., Lee, D. S., and Lim, L.: Flying into the future: aviation emissions scenarios to 2050, Environ. Sci. Technol., 44, 22552260, doi:10.1021/es902530z, 2010.

Rädel, G. and Shine, K. P.: Evaluation of the use of radiosonde humidity data to predict the occurrence of persistent contrails, Q. J. Roy. Meteor. Soc., 133, 1413-1423, doi:10.1002/qj.128, 2007.

Rädel, G. and Shine, K. P.: Radiative forcing by persistent contrails and its dependence on cruise altitudes, J. Geophys. Res., 113, D07105, doi:10.1029/2007JD009117, 2008.

Rädel, G. and Shine, K. P.: Validating ECMWF forecasts for the occurrence of ice supersaturation using visual observations of persistent contrails and radiosonde measurements over the UK, Q. J. Roy. Meteor. Soc., 136, 1723-1732, doi:10.1002/qj.670, 2010.

Riahi, K., Grübler, A., and Nakicenovic, N.: Scenarios of longterm socio-economic and environmental development under climate stabilization, Technol. Forecast. Soc., 74, 887-935, doi:10.1016/j.techfore.2006.05.026, 2007.

Riahi, K., Rao, S., Krey, V., Cho, C., Chirkov, V., Fischer, G., Kindermann, G., Nakicenovic, N., and Rafaj, P.: RCP 8.5 - a scenario of comparatively high greenhouse gas emissions, Climatic Change, 109, 33-57, doi:10.1007/s10584-011-0149-y, 2011.

Schumann, U.: On conditions of contrail formation from aircraft exhausts, Meteorol. Z., 5, 4-23, 1996.

Schumann, U.: Influence of propulsion efficiency on contrail formation, Aerosp. Sci. Technol., 4, 391-401, 2000.

Schumann, U., Busen, R., and Plohr, M.: Experimental test of the influence of propulsion efficiency on contrail formation, J. Aircraft, 37, 1083-1087, 2000.

Schumann, U., Graf, K., and Mannstein, H.: Potential to reduce the climate impact of aviation by flight level changes, 3rd AIAA Atmospheric Space Environments Conference, 27-30 June 2011, Honolulu, Hawaii, USA, 1-22, 2011.

Sherwood, S. C., Ingram, W., Tsushima, Y., Satoh, M., Roberts, M., Vidale, P. L., and O'Gorman, P. A.: Relative humidity changes in a warmer climate, J. Geophys. Res., 115, D09104, doi:10.1029/2009JD012585, 2010.

Soler, M., Zou, B., and Hansen, M.: Flight trajectory design in the presence of contrails: application of a multiphase mixed-integer optimal control approach, Transport. Res. C-Emer., 48, 172-194, doi:10.1016/j.trc.2014.08.009, 2014.

Spichtinger, P., Gierens, K., Leiterer, U., and Dier, H.: Ice supersaturation in the tropopause region over Lindenberg, Germany, Meteorol. Z., 12, 143-156, 2003a.

Spichtinger, P., Gierens, K., and Read, W.: The global distribution of ice-supersaturated regions as seen by the microwave limb sounder, Q. J. Roy. Meteor. Soc., 129, 3391-3410, 2003 b.
Spichtinger, P., Gierens, K., and Wernli, H.: A case study on the formation and evolution of ice supersaturation in the vicinity of a warm conveyor belt's outflow region, Atmos. Chem. Phys., 5, 973-987, doi:10.5194/acp-5-973-2005, 2005.

Sridhar, B., Chen, N. Y., and Ng, H. K.: Energy efficient contrail mitigation strategies for reducing the environmental impact of aviation, 10th USA/Europe Air Traffic Management Research and Development Seminar, 212, 10-13 June 2013, Chicago, Illinois, USA, 2013.

Stevens, B., Giorgetta, M., Esch, M., Mauritsen, T., Crueger, T., Rast, S., Salzmann, M., Schmidt, H., Bader, J., Block, K., Brokopt, R., Fast, I., Kinne, S., Kornblueh, L., Lohmann, U., Pincus, R., Reichler, T., and Roeckner, E.: Atmospheric component of the MPI-M earth system model: ECHAM6, JAMES, 5, 146172, doi:10.1002/jame.20015, 2013.

Taylor, K. E., Stouffer, R. J., and Meehl, G. A.: An overview of CMIP5 and the experiment design, B. Am. Meteorol. Soc., 93, 485-498, doi:10.1175/BAMS-D-11-00094.1, 2012.

Thorne, P. W., Lanzante, J. R., Peterson, T. C., Seidel, D. J., and Shine, K. P.: Tropospheric temperature trends: history of an ongoing controversy, WIREs Clim. Change, 2, 66-88, doi:10.1002/wcc.80, 2011.

Tompkins, A. M., Gierens, K., and Rädel, G.: Ice supersaturation in the ECMWF integrated forecast system, Q. J. Roy. Meteor. Soc., 133, 53-63, 2007.

Watanabe, M., Suzuki, T., O'ishi, R., Komuro, Y., Watanabe, S., Emori, S., Takemura, T., Chikira, M., Ogura, T., Sekiguchi, M., Takata, K., Yamazaki, D., Yokohata, T., Nozawa, T., Hasumi, H., Tatebe, H., and Kimoto, M.: Improved climate simulation by MIROC5: mean states, variability, and climate sensitivity, J. Climate, 23, 6312-6335, doi:10.1175/2010JCLI3679.1, 2010.

Wilkerson, J. T., Jacobson, M. Z., Malwitz, A., Balasubramanian, S., Wayson, R., Fleming, G., Naiman, A. D., and Lele, S. K.: Analysis of emission data from global commercial aviation: 2004 and 2006, Atmos. Chem. Phys., 10, 6391-6408, doi:10.5194/acp-10-6391-2010, 2010.

Williams, V., Noland, R. B., and Toumi, R.: Reducing the climate change impacts of aviation by restricting cruise altitudes, Transport. Res. D-Tr. E., 7, 451-464, 2002.

Wright, J. S., Sobel, A., and Galewsky, J.: Diagnosis of zonal mean relative humidity changes in a warmer climate, J. Climate, 23, 4556-4569, doi:10.1175/2010JCLI3488.1, 2010.

Zou, B., Buxi, G. S., and Hansen, M.: Optimal 4-D aircraft trajectories in a contrail sensitive environment, Netw. Spat. Econ., doi:10.1007/s11067-013-9210-x, online first, 2015. 